Publisher homepage: www.universepg.com, ISSN: 2663-7529 (Online) \& 2663-7510 (Print)

https://doi.org/10.34104/ejmhs.020.16020

European Journal of Medical and Health Sciences

Journal homepage: www.universepg/journal/ejmhs

\title{
Prescribing Pattern of Medical Practitioners in Their Private Chamber Practice According to WHO Prescribing Indicators in a Southern District of Bangladesh
}

\author{
Sanjoy Saha ${ }^{*}$, ASM Rizwan ${ }^{2}$, Jyoti Vaskar Saha ${ }^{3}$, Abu Rayhan Siddique ${ }^{4}$, Abu Hasnat ${ }^{5}$, Mahbobur \\ Rahman $^{6}$, Wazed Ahmed ${ }^{7}$, and Dil Afroz ${ }^{8}$ \\ ${ }^{1}$ Dept. of Pharmacology and Therapeutics, Ad-din Sakina Women's Medical College, Jashore and PhD fellow, Bangladesh \\ University of Professionals, Dhaka, Bangladesh; ${ }^{2}$ Dept. of Medicine, Ad-din Sakina Women's Medical College, Jashore, \\ Bangladesh; ${ }^{3}$ Dept. of Nephrology, Dhaka Medical College, Dhaka, Bangladesh; ${ }^{4}$ Dept. of Surgery, Shaheed Taj Uddin \\ Ahmed Medical College, Gazipur, Bangladesh; ${ }^{5}$ Dept. of Pediatric Nephrology, Dhaka Shishu Hospital, Dhaka, Bangladesh; \\ ${ }^{6}$ Mymensingh Medical College, Mymensingh, Bangladesh; ${ }^{7}$ Neonatal ICU, Lab Aid Hospital, Dhaka, Bangladesh; and ${ }^{8}$ Dept. \\ of Gynaecology and Obstetrics, Jahurul Islam Medical College, Kishoreganj, Bangladesh. \\ *Correspondence: dr.sanjoysahammc@gmail.com (Dr. Sanjoy Saha, Associate Professor and Head, Dept. of Pharmacology \\ and Therapeutics, Ad-din Sakina Women's Medical College, Jashore, Bangladesh)
}

\begin{abstract}
Prescription is a written order and direction by a registered physician to the pharmacist for the particular use of a medicine product for a patient. The aim of the research was to observe the prescription pattern of doctors in their chamber practice according to World Health Organization (WHO) prescribing indicators. A total of 300 prescriptions of outdoor patients from various departments of different private chambers of medical practitioners were collected from $1^{\text {st }}$ August to $31^{\text {st }}$ October 2019 and were evaluated. After evaluation and data analysis we got, patients' age and gender were not mentioned in $6 \%$ prescriptions. Dose and course of treatment were incomplete in $60 \%, 72 \%$ and $52 \%$ of prescriptions respectively. Abbreviations were used in $100 \%$ prescriptions. Doctor's medical registration number was mentioned in 13\% prescriptions only. Total 1042 drugs were prescribed in 300 prescriptions. The average number of drugs prescribed was $3.38 \pm 1.79$ (Mean $\pm \mathrm{SD}$ ). Most of the prescriptions contained a brand name (93.33\%) of the drugs whereas only a few (6.7\%) used the generic names $(\mathrm{P}<0.05)$. Antibiotics and injections were ordained in $64 \%$ and $8 \%$ cases respectively. Approximately $60 \%$ drugs were prescribed according to the Essential Medicine List (EML) of Bangladesh. Our study has shown that very few physicians are acquainted and follows the WHO standard of prescribing which can lead to serious negative health consequences. Moreover, the presence of antibiotics in two-third of all prescriptions should ring an alarm to prevent its aberrant use.
\end{abstract}

Keywords: Rational prescribing, Private practitioner, Prescribing indicators, Pattern, and WHO.

\section{INTRODUCTION}

Prescription is written medico-legal document by authorized person for the treatment of patient where each prescription should contain all the four elements, superscription, subscription, inscription and signature with registration number issued by medical council 
(Sampling to Study Drug Use, WHO, 2000). In superscription, information of doctor (qualification, address) and patient (name, age, sex address) as well as date of prescription are included (Uddin et al., 2014). The subscription of a prescription includes to the information of prescribed drugs such as dosage form, drug name, dose, number etc. And in inscription directions for the use of drug are mentioned. Finally, signature of the registered medical practitioner with their registration number at medical council should be written as last element of prescription. All prescription orders should be clearly written by prescriber so that it can easily communicate between pharmacist and patient. Prescribing errors can be observed if sufficient and necessary information are not mentioned in prescription (Lesar et al., 1997)

Prescribing errors causes the irrational utilize of drugs and reduce patient compliance (Fijn et al., 2002). Study by Kuo et al. described that $70 \%$ prescribing errors was noticed among USA family physicians while study managed at West England reported that $43.8 \%$ prescriptions accommodate one or more prescribing errors (Kuo et al., 2008; and Seden et al., 2013). Study carried out at Nasik, India described that out of 300 prescriptions 279 prescriptions (93\%) were irrational based on the utilize of essential drug WHO and standard treatment guidelines (Chaudhari et al., 2011). Prescribing is a complex task requiring diagnostic skills, knowledge of medicines, an understanding of the principles of clinical pharmacology, communication skills, appreciation of risk and uncertainty (Khan and Ara, 2011). Irrational use of medicines is a global problem and common finding, particularly in developing country like Bangladesh. Poly-pharmacy, unnecessary use of antimicrobials, over use of injections and vitamins are commonly evident (Islam et al., 2020). On the other hand, aggressive drug marketing, lack of information drug use and inadequate drug supply has been suggested to be the main causes behind the irrational prescribing (Begum et al., 2012).

The high cost of prescribed drug causes problems in developing countries like Bangladesh. This problem can be minimized by prescribing drugs by generic name and selection of drugs from essential medicine list (Sharif et al., 2019). Generic drugs are substitute of branded drug without any patient protections with similar efficacy but 40 to $60 \%$ cheaper than branded drugs (Siddarth et al., 2014). Irrational drug use leads to reduction in the quality of drug therapy, wastage of resources, increased treatment costs, increased risk for adverse drug reactions and emergence of drug resistance (Rahman et al., 2019). According to WHO prescribing indicators includes number of drugs prescribing per prescription, percentage of drugs prescribed by generic name, percentage of encounter by injection and antibiotics prescription and percentage of drugs prescribed from EML.

\section{MATERIALS \& METHODS}

Samples of prescriptions (by private practitioners) were collected from patients randomly. Prescriptions were collected either by photocopying or scanning by Smartphone after taking informed written consent from respective patients. A total of 300 prescriptions were the study sample. We had carried out Z-test. Variables were described as numbers and percentages. $\mathrm{P}=0.05$ was considered as statistically significant. The Statistical Package for Social Sciences (SPSS) version 20.0 was used to analyze data.

Prescriptions were not categorized according to patients' details like age, sex or disease profile. Afterwards all prescriptions (300) were analyzed using the WHO indicators. Following parameters were analyzed- a) Average numbers of drugs per prescription, b) Percentage of drugs prescribed by generic name, c) Percentage of prescriptions with an antibiotic prescribed, d) Percentage of prescriptions with an injection prescribed, and e) Percentage of drugs prescribed from essential drug list.

\section{RESULTS}

Patients' descriptions such as age and gender were not found in $6 \%$ prescriptions. It was evidenced that dose, direction of drug and duration of treatment was not completely mentioned in $60 \%, 72 \%$ and $52 \%$ of prescriptions respectively. Abbreviations were used in $100 \%$ prescriptions. Doctor's medical registration number was mentioned in $13 \%$ prescriptions. Total 
1042 drugs were prescribed in 300 prescriptions. Average number of drug prescribed was $3.38 \pm 1.79$ $($ Mean \pm SD).
Brand name was used in $93.33 \%$ prescriptions and generic name in $6.7 \%$ prescriptions. Use of antibiotics and injections was $64 \%$ and $8 \%$ respectively.

Table 1: Analysis of prescription according to WHO prescribing indicators $(n=300)$

\begin{tabular}{|l|c|}
\hline \multicolumn{1}{|c|}{ WHO prescribing indicators } & Prescription analysis \\
\hline Average number of drugs per prescription (Mean \pm SD) & $3.38 \pm 1.79$ \\
\hline Percentage of drugs prescribed by generic name & $6.67 \%$ \\
\hline Prescribed by brand name (in \%) & $93.33 \% *$ \\
\hline Antibiotic prescribed (in \%) & $64 \%$ \\
\hline Injection prescribed (in \%) & $8 \%$ \\
\hline Prescribed from essential medicines list (in \%) & $60 \%$ \\
\hline \multicolumn{2}{|c|}{$* 0.05$ significantly compared to generic name by Z-test } \\
\hline
\end{tabular}

\section{DISCUSSION}

300 prescriptions were analyzed by using some of the WHO indicators. According to that analysis our study revealed that there was not fully complete prescription was found. Patient's names, address, date of prescription were mention in $100 \%$ prescriptions. Similar to report showed by Siddarth et al., where it was $99.3 \%$. Gender, age and address of patient were missing in $6 \%$ the prescriptions similar to study conducted at Maharashtra14 while Siddarth et al., reported that in $33 \%$ and $0.7 \%$ prescriptions address and gender were missing. Study conducted at Ethiopia (Desta and Abdulwhab, 1996) and Dubai (Sharif et al., 2008) reported that age, gender were not mentioned in $36.6 \%, 18.6 \%$ and $9.7 \%, 12 \%$ respectively which was higher as compared to our study. In this study, on an average, 3.38 drugs were prescribed per prescription, which was 3.81 in a study conducted in 2009 and 3.24 in another study conducted in 2011 (Rahman et al., 2009 and Paul et al., 2011).

In an Indian study, the average number of drugs in a prescription was 3.128. In the current study, only $0.20 \%$ drugs were prescribed under generic names but Paul et al.; and Alam et al. reported it to be $0.13 \%$ and 1.33\% respectively (Paul et al., 2011; and Alam et al., 2011). In an Indian study it was $4.24 \%$, which was $44 \%$ in Nepal study (Kafle, 1992). In our study $64 \%$ prescriptions were prescribed with antimicrobials. This finding is quite similar with the study Rahman et $a l ., 2009$, where the result was $72.50 \%$. In the study, about $64 \%$ of the drugs were prescribed from the Essential Drug List. Paul et al., 2011 and Baqui and Choudhury have reported that respectively $48.35 \%$ and $49 \%$ of prescribed medicines were from EDL (Paul et al., 2011). About 8\% prescriptions contained an injection which was almost similar with the study done by Saurabh et al. About $60 \%$ prescriptions were provided with proper instructions regarding drug dosing, formulation and duration, which was $70 \%$ in the study of Rahman et al.

On the other hand only $6 \%$ prescriptions contained proper instructions about patient medication information and advice like side effects of the prescribed drugs, other relevant advice and follow up of the patients (Shahen et al., 2019). These patient medication information parameters were $17.5 \%$ in the study Paul et al., 2011 and 35.68\% prescriptions follow the proper instructions about prescription format. Irrational prescribing is a habit that is difficult to cure. However, prevention is possible. Intervention is needed to improve prescribing behaviors of doctors such as short problem based training course in pharmacotherapy and rational use focused workshops can improve prescription behavior and skills (Vries et al., 1995; and Thomas et al., 1997). Clear and comprehensives rules should be formulated and implemented by the government to ensure rational prescribing. 


\section{CONCLUSION}

Bulk of the prescriptions we studied, failed to meet WHO standard and antibiotics were surprisingly the commonest prescribed medication compared to other group of drugs. Although it is not a large scale study, our study reflects these two prescribing issues that need to be addressed. We advocate proper monitoring of good prescribing practice and strict regulation of antibiotic use policy in private chambers of medical practitioners throughout the country to enhance optimum patient care.

\section{ACKNOWLEDGEMENT}

We are grateful and acknowledging the support from the medical practitioners whose prescriptions was collected for evaluation.

\section{CONFLICT OF INTEREST}

The authors declare that they have no conflict of interests to publish the present research work.

\section{REFERENCES}

1. Alam MM, Parveen F, Ara F, Iqbal MJU and Saha RR. (2011). 'Prescribing trends in the outpatient department in a tertiary hospital in Bangladesh', $B M J, 40(2), 8-12$.

2. Begum F, Uddin MR, Islam MMSU, Sarker MN, Barman RC and Ali MY. (2012). 'Evaluation of Prescribing Pattern of the Private Practitioners in Bangladesh' Journal of Faridpur Medical College, 7(2), 51-53.

3. Chaudhari V, Chaudhari B, Khairnar A. (2011). 'A Cross-Sectional Prescription Audit Database for Anti-Anginal Drugs with Impact of Essential Drug List and Standard Treatment Guidelines on Prescription Pattern in Nasik City', Research J. Pharm and Tech. 4(7), 111114.

4. Desta Z, Abdulwhab M. (1996). 'Prescriptions writing in Gondar outpatient teaching hospital, Ethopia.' East Afr. Med. J. 73(2), 115-59.

5. Fijn R, Van den Bemt PMLA, Chow M, De Blaey CJ, De Jong-Van den Berg LTW and Brouwers JRBJ. (2002). 'Hospital prescribing errors: epidemiological assessment of predictors', BJCP, 53(3), 326-31.
6. Islam R, Hossain MN, Alam MK, Uddin ME, Rony MH, Imran MAS. (2020). Antibacterial Activity of Lactic Acid Bacteria and Extraction of Bacteriocin Protein. Advances in Bioscience and Biotechnology, 11(2), 49-59. https://doi.org/10.4236/abb.2020.112004

7. Kafle KK and members of Inrud Nepal Core Group, (1992). 'Inrud drug use indicators in Nepal: Practice patterns in health posts in four districts', INRUD News, 3(1), 15.

8. Khan MI, Ara N. (2011). 'Promoting rational prescribing among medical practitioners', $B M J$, 40(2), 6-7.

9. Kuo GM, Phillips RL, Graham D and Hickner JM. (2008). 'Medication errors reported by US family physicans and their office staff', Qual. Saf. Health Care, 17, 286-90.

10. Lesar TS, Briceland L, Stein DS. (1997). 'Factors Related to Errors in Medication Prescribing', JAMA, 277(4), 312-7.

11. Paul PC, Pal DR, Rahman MM, Islam MJ and Siddique AR. (2011). 'Evaluation of prescribing practices in outpatient department of teaching hospital', BMJ, 40(2), 19-22.

12. Rahman Z, Nazneen R, Begum M. (2009). 'Evaluation of prescribing pattern of the private practitioners had done by the undergraduate medical students', Bangladesh J. Pharmacol. 4, 73-5.

13. Rahman MA, Haque A, Ahmad T, Mahmud S, Sohana SN, Hossain MR, Barman NC, Badiruzzaman M, Hossain T, Haque MS, Uddin ME, and Ahmed R. (2019). Isolation, Identification and Antibiotic Sensitivity Pattern of Salmonella spp. from Locally Isolated Egg Samples. Amer. J. of Pure and Appl. Biosci., 1(1), 1-11. https://doi.org/10.34104/ajpab.019. 019111

14. Seden K, Kirkham JJ, Kennedy T. (2013). 'Cross-sectional study of prescribing errors in patients admitted to nine hospitals across North West England', BJM Open, 3: e002036.

15. Shahen MZ, Mahmud S, Rony MH, Sohana SN, Imran MAS, Al Maruf MA, Azim MAA, Islam MM, Islam MR, Uddin ME and Alam MS. (2019). Effect of Antibiotic Susceptibility and Inhibitory Activity for the Control of 
Growth and Survival of Microorganisms of Extracts of Calendula officinalis. Europ. J. of Med. and Health Sci., 1(1), 1-9. https://doi.org/ 10.34104/ejmhs.019

16. Sharif SI, Al-Shaqra M, Hajjar H, Shamout A and Wess L. (2008). 'Patterns of drug prescribing in a Hospital in Dubai, United Arab Emirates', Libyan J. Med, 3, 10-12.

17. Sharif IH, Tamanna S, Mosaib MG, Tamanna $\mathrm{N}$, Haque MA, Jamal MAHM, and Uddin ME. (2019). Assessment and Biomonitoring of the Effect of Rapeseeds Oil on Wister Rat Organs. Amer. J. of Pure and Appl. Biosci., 1(4), 20-29. https://doi.org/10.34104/ajpab.019.0192029

18. Siddarth V, Arya S, Gupat SK. (2014). 'A study of prescribing practices in outpatient department of an apex tertiary care institute of India', Int. J. Res. Foundation Hosp. Health Adm. 2(1), 31-35.

19. Thomas M, Cherian AM, Mathai D. (1997).
'Measuring the impact of focused workshops on rational drug use, Trop. Doct. 27, 206-10.

20. Uddin ME, Maitra P, Faruquee H. M., Alam MF. (2014). Isolation and Characterization of Proteases Enzyme from Locally Isolated Bacillus sp. American J. of Life Sciences, 2(6): 338-344. https://doi.org/10.11 648/j.ajls.20140206.12

21. Vries De TP, Henning RH, Hogerzeil HV, Bapna JS, Bero L and Kafle KK. (1995). 'Impact of a short course in pharmacotherapy for undergraduate medical students', An international randomized controlled study, Lancet, 346, 1454-7.

22. WHO (2008), Sampling to Study Drug Use, 2000. http://archives.who.int/PRDUC2004/RD UCD/TOC.html (archived July 2008).

Citation: Saha S, Rizwan ASM, Saha JV, Siddique AR, Hasnat A, Rahman M, Ahmed W, and Afroz D. (2020). Prescribing pattern of medical practitioners in their private chamber practice according to WHO prescribing indicators in a southern district of Bangladesh. Eur. J. Med. Health Sci., 2(2), 16-20. https://doi.org/10.34104/ejmhs.020.16020 C) () 